\title{
MANAGERIAL ETHICS AS SOFT POWER TOOL FOR ORGANIZATIONS IN DEFENSE AND SECURITY AREAS
}

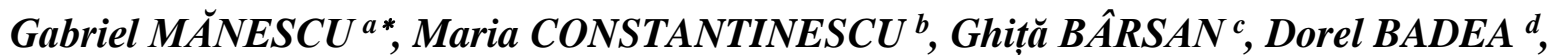 \\ Dumitru IANCU ${ }^{e}$ \\ a, c, d, e "Nicolae Bălcescu” Land Forces Academy, Sibiu, Romania \\ ${ }^{b}$ Regional Department of Defense Resource Management Studies, Brasov, Romania
}

DOI: $10.24818 / \mathrm{IMC} / 2020 / 05.05$

\begin{abstract}
The paper aims to present some defining aspects regarding the managerial ethics customized to the specifics of institutions in the field of national defence and security, aspects that emerged from an extensive study that investigated the current and prospective state of leadership science in the military. The review of the main types of ethics, of the representative schools and of the fundamental principles of ethics is the foundation of the investigative approach and is meant to recall the concepts that govern this field and to ensure the transition to practical aspects of ethics in the military organization. It exemplifies a series of activities specific to the military field that require special attention from the perspective of applying the fundamental principles of ethics, activities to which the military body pays special attention due to the way they are perceived by civil society. The presentation of the results of the study allows an $x$-ray of the way in which ethical management is perceived at different hierarchical levels, depending on the managerial experience gained, but also depending on the military specialization. Moreover, the results can foreshadow the necessary measures to be taken in what regards ethical management specific to the military field.
\end{abstract}

KEYWORDS: Defense, Ethics, Management, Military Leader

\section{DIVERGENCES AND CONVERGENCES IN THE CONCEPTUALIZATION AND APPLICATION OF ETHICS IN MANAGEMENT}

The term ethics comes from the Greek word ethos, meaning character, and is most often used as referring to the philosophical approach focused on "systematizing, defending, and recommending concepts of right and wrong behaviour" (Fieser, 2009).

The concept of ethics is by no means limited to abstract philosophical considerations, as it is closely linked to any kind of human endeavour and area of activity - business, management, religion, environment, defence, etc. Any human decision and action can be evaluated from the point of view of ethics, through the analysis of its implications on other people and the external environment. Management ethics is mainly linked to decision making so that each course of action chosen is the "good" one, in order to mitigate the potential negative results.

An ethical decision from a management point of view may involve choosing between decisions that benefit the majority and those that only benefit an influent minority, prioritizing or not profit or shareholders' interests over the employees' interests, achieving a short-term target versus reducing long-term costs, whether or not to take into account externalities, to give just a few examples. Managerial ethics involves the application of ethical and moral principles to the management activity (in the business or governmental area). It does not involve a set of separate ethical

\footnotetext{
* Corresponding author. E-mail address: manescug@yahoo.com
} 
principles, but it considers the way the existing principles are applied in solving the specific problems that arise in the management activity.

Such challenges may stem from various areas related to the management activity, as exemplified below (the list is obviously not exhaustive):

- Decisions regarding the prioritization of the organization's short-term interests (profit, achievement of sales targets or objectives) versus long-term objectives (investments for development, improvement of working conditions, creation of a healthy organizational culture, etc.);

- Decisions regarding the prioritization of personal interests of specific interest groups (management personnel, shareholders) versus the general interests of all members of the organization (employees);

- Decisions regarding the prioritization of the organization's interests versus the broader society interests (e.g. payment of dividends to shareholders versus investing in equipment to reduce pollution, decisions regarding repatriation of profit);

- Decisions regarding the stipulations in the internal regulations and the values that underline the organizational culture;

- Decisions regarding the observance of the legal framework in force versus finding gaps in the law that would allow its circumvention, etc.

Managerial ethics is sometimes considered an oxymoron (especially by the promoters of the neoliberal economic current or the libertarian philosophy), a barrier to achieving the main objective of a private company - the profit. For example, the neo-liberal economic school embraces this approach (albeit in a simplistic way, as the assumption of free competition is not a realistic one), considering, according to its founder, that "there is one and only one social responsibility of business to use its resources and engage in activities designed to increase its profits so long as it stays in the rules of the game, which is to say, engages in open and free competition, without deception or fraud" (Friedman, 1962, 133). As the neo-liberal school supports minimizing the role of the state, they extend the reasoning to the entire society.

In a simplistic approach to how the application of managerial ethics in the field of defense can be made explicit, non-specialists can also consider it an oxymoron, starting from the simple presumption that "only victory matters in a battle". Absolutely false. As for any economic organization the ultimate goal is to obtain / increase profit (but with strict compliance with legislation or internal rules), the fundamental mission of the military organization is to ensure security, preserve independence and national sovereignty and defend alliance partners. We can say that the raison d'être of the military organization, its purpose and missions cannot really be assumed and fulfilled without strict observance of the national and international legislation in the field. It is good to know that every military operation, from the planning phase, fully respects and applies the requirements of the so-called "Rules of Engagement", which are designed to ensure the maintenance of organized force under the control of reason, of the armed forces under the control of national command and, through it, under the control of the nation.

However, if an organization / manager fail to consider the ethical principles in decision making and their activity, the organization may sooner or later incur various types of costs, deriving from employee theft, fines, legal costs from law suits, decreased employee productivity, morale and loyalty, large staff turnover, difficulties in hiring well-trained employees, loss of image and reputation, etc.

The classical approach to ethical theory identifies three main areas: meta-ethics, normative ethics and applied ethics (Fieser, 2009).

Meta-ethics focuses on issues related to the source and meaning of a person's ethical principles. A manager's ethical principles may come from within the organization, from the family or religious environment. Meta-ethics focuses on concepts such as values perceived as universal, the will of God, the role of reason in issuing ethical judgments, but also on the definition of the terms used in 
describing the concept (Fieser, 2009). Therefore, the meta-ethics approach applied to managerial ethics means the analysis of a manager's actions and of their consistency (or lack thereof) with which he/she applies a set of ethical principles in his/her professional life, in certain specific situations, but also in personal decisions, throughout his/her life.

Normative ethics is a more practical approach, as it focuses on establishing and evaluating ethical rules of behaviour and decision making, a person's duties and responsibilities, but also the consequences of specific behaviours and actions on others. From the point of view of managerial ethics, this means observing behaviours / actions with negative effects on the individuals, teams or organizations and the development of rules, regulations, procedures, etc. that can mitigate ethical problems and encourage decision making in an ethical context.

Applied ethics consists of a bunch of disciplines that try to philosophically analyze situations and dilemmas in the real world. A central role in applied ethics is played by case-based argumentation. In certain cases, the aim is to identify convergences between analyses made from the perspective of different ethical theories.

The various philosophical schools of thought that have emerged over time can also be are also used as guidelines for developing a framework for managerial ethics and helping managers to act in an ethical manner.

Utilitarianism is one of the most influential schools of thought, belonging to the field of normative ethics. Its best-known proponents were Jeremy Bentham and John Stuart Mill. There are several approaches to this philosophical school, but, generally, utilitarianism postulates that a moral action is useful (produces beneficial results) for the majority-one has to assess the consequences of an action not just for the individual (that would be selfish), but for all the members of the organization / society (Driver, 2014).

Jeremy Bentham proposes the principle of utility as a standard of a "right" action for governments and individuals. Nonetheless, he was aware of the intrinsic contradiction of utilitarianism, between the individual desire to obtain benefits and to avoid costs and the implementation of the same principle at the organization / society level. The psychological selfishness (the individual pursuit of benefits / pleasure) is sometimes incompatible with promoting the welfare of other people (Bentham, 1907). Furthermore, focusing exclusively on the outcome can lead to Machiavellianstyle managerial approaches, following the principle that "the end justifies the means".

From the point of view of managerial ethics, utilitarianism involves a careful analysis of the costs and benefits of a decision / action, deciding what means fair and ethical, and establishing if the benefits outweigh the costs for the majority of an organization's members. Therefore, a manager who would apply the principles of utilitarianism should consider:

- Clearly identifying the organization's goals and its main reason of existence;

- Identifying alternatives and analyzing the costs and benefits of each course of action for the various groups of people who will be influenced by the decision;

- Analysing the collective and individual interests;

- Identifying $I$ the consequences (outcomes) of a decision / course of action in a clear and comprehensive manner.

Universalism, another school of thought that may be useful for defining the framework of managerial ethics, is based mainly on the ideas of Immanuel Kant (1964) and on the basic principle that the purpose does not justify any means, no matter how beneficial it would be to the majority.

Kant considers that action performed on the basis of a morally valuable maxim is action "according to duty" (Duty ethics). Such an action becomes a duty, defined as "rules or laws of some sort combined with some sort of felt constraint or incentive on our choices, whether from external coercion by others or from our own powers of reason" (Johnson \& Cureton, 2019) and its omission is forbidden. Obviously, many of these actions comply with the concept of duty, although they were 
not performed out of obligation. However, even this notion of apparent obligation is considered indispensable in a situation for the individual acting based on duty.

The universalist approach is based on the concept of duty and the use of principles such as justice, fairness, honesty and respect.

Therefore, a managerial action / decision is ethical if it complies with a set of moral criteria clearly established and acknowledged beforehand by all the members of the organization. The moral benchmarks presented above are more commonly found in the military organizational culture than in the business environment. By definition, a military organization may be put in a position to violate some of the basic moral-religious precepts (such as not to kill), in order to fulfil its existential purpose. Military organizations build their ethical principles on the basis of the universal concept of ethics based on duty or on the observance of the rules of conduct. An action will be ethical if it has been carried out in compliance with the rules / regulations / orders.

Managerial ethics from a universalist point of view implies:

$>$ Establishing and abiding by a clear set of rules that govern a group / organization;

$>$ Assessing the behaviour of the organization's members in compliance with the rights and duties established by these rules;

$>$ Identifying situations in which non-compliance with the rules may affect individuals or organizations as a whole;

$>$ Clearly establishing duties / rights for each employee;

$>$ Identifying the consequences that each action / decision taken to reach a final goal (no matter how commendable it may be) has on the individuals/ organization.

Another approach to ethics aims at bringing the concept of individual or collective rights to the foreground. This school of thought considers that an ethical approach involves respecting and guaranteeing individual rights, such as freedom of expression, freedom of choice, self-respect, etc. In other words, it emphasizes respecting human rights (McCloskey, 1965; Tuck, 1979; Shue, 1981; Stoljar, 1984).

From the perspective of managerial ethics, this implies that managers should be guided in their decisions and activities by a humanistic vision, meaning they should consider:

$\checkmark$ Identification of individual rights that could be infringed by a certain decision / action;

$\checkmark$ Establishing the moral and legal basis of these rights;

$\checkmark$ Establishing moral principles for building a framework that limits the use of utilitarian approach in the situations where a person's rights might be infringed.

Managerial ethics can also use the principles of the ethical approach focusing on the concepts of fairness and justice. Based on the ideas of John Rawls (1971), this approach is centred upon two guiding principles. First, every person has equal rights to benefit from the maximum number of freedoms and rights that are compatible with other individuals' freedoms and rights. Second, economic and social inequalities must be reduced by making various job positions and functions accessible to all those who are qualified to fill them.

From this perspective, managerial ethics should focus on considering whether a management decision/action leads to an equitable and fair distribution of duties and benefits, among all the members of the organization, by:

- analysing how each action / decision will lead to an equitable distribution of costs and benefits between the various categories of personnel, between the management and execution staff, between employees and shareholders, between the various stakeholders;

- establishing and implementing procedures for equitable distribution of costs and benefits, duties and rights;

- identifying the individuals / groups that will be adversely affected by a certain decision / action and the specific ways in which this situation can be remedied from the point of view of equity.

The approach based on the concept of character, also known as the ethics of virtue, considers that ethical behaviour derives from character traits such as honesty, integrity, self-discipline, etc. This 
approach is a classic one, founded by the ancient philosophers Plato and Aristotle, and also includes concepts pertaining to Chinese philosophy. The approach posits that certain character traits or virtues require a person to behave, think and act in a certain way, based on complex mental constructs (Hursthouse \& Zalta, 2003).

Therefore, from the point of view of managerial ethics, this means that any decision / action / plan is ethical if it reflects a set of virtues unanimously agreed upon. This approach is perhaps the least pragmatic in the conditions of the modern world and in management context, as it assumes that individuals get to occupy management positions only if they have specific character traits / virtues and that they act exclusively based on these principles. As a result, any other considerations related to the achievement of the organization's purpose, profit, competition, etc. become secondary.

Beyond the philosophical considerations, all three approaches can be useful in analyzing managerial ethics, if we keep in mind the final purpose of the analysis: identifying ethical benchmarks for individual/group actions, as well as building a beneficial, non-toxic organizational culture. Analyzing case studies, raising ethical issues or trying to find answers to certain questions may help in establishing principles, values, and rules to help make decisions before proceeding to action.

These are not aimed at giving strict guidelines to shape an individual's behaviour in regard to what means ethical or unethical behaviour, but at helping the individual/organization to clarify the specific ethical framework in which they evolve. Nobody can predict with certainty the various ethical dilemmas that may occur during the day-to-day activities of an organization and how one should react to them. Each person will have his/her own set of rules and values, which may differ from one context to another, and no internal regulation will be able to substitute for solid individual ethical principles regarding the responsibility of one's own actions.

However, raising awareness on the importance of managerial ethics, identifying lessons from case studies, discussing or analyzing concepts, may help clarify ethical principles and provide an overview on how each individual actions affect the system (the team, organization or its external environment - customers, partners, the entire society).

An analysis of the implications of managerial ethics cannot be conducted without a clear identification of the organization's reason of existence. As no organization can function autonomously, its purpose should be correlated with the purpose of the larger system within which it functions.

For example, the purpose of a private company is to make a profit and distribute it to the shareholders, through dividends. But is it ethical for a private company to fulfil its profit-related purpose by exploiting its employees, circumventing the law by not paying taxes to the state budget, by obtaining raw materials from dubious sources or by producing serious damage to the environment?

The stated purpose of the military organization is to defend the national integrity and sovereignty, but it is ethical to achieve this goal by using weapons of mass destruction or by issuing morally reprehensible orders, such as the use of torture to obtain information?

What criteria can managers use in this case to make ethical decisions? Velasquez (1998) proposes three criteria to systematize and structure ethical reasoning:

$>$ The ethical reasoning must be logical, and the premises and assumptions on which it is based must be clearly established and stated;

$>$ The factual evidence used to support ethical reasoning must be accurate, relevant and complete;

$>$ The ethical standards used in reasoning must be consistent, and when disagreements occur in the standards of a decision-making manager, it is necessary to re-analyze and modify the standards.

Managerial ethics must address a fundamental question: if and to what extent an organization and its managers have social responsibility. Buono and Nicholas (1990) identify four ethical approaches to social roles and decision-making. 
They approach the analysis of managerial ethics from the perspective of:

- two models: the model of the stakeholder (which stipulates that the organization's social responsibility refers to the wider responsibility of the stakeholders) and the model of the shareholder (which stipulates that the organization's social responsibility is narrower, referring only to shareholders)

- two sets of reasons that underpin these approaches: selfish interest and moral duty.

By combining these models and reasons, Buono and Nicholas (1990) identify four types of social responsibility models:

1. Productivism, as the name implies, considers an organization's social responsibility only from the selfish and rational point of view of satisfying the shareholders. This approach advocates that any organization must make a profit (promoting neo-liberal capitalism, in which the role of the state and non-profit organizations is minimized). Free market and competition would be the only guidelines for ethical managerial conduct. However, the assumption on which this approach is based (the existence of a free market and perfect competition) is not realistic, as in the real world there are many factors that distort the free functioning of the markets: the interest groups with quasi- monopoly power, corruption, inequalities in access to capital and information, etc.

2. The philanthropy approach stipulates that the main social responsibility of an organization remains the profit, but that there is also a moral duty to help the most vulnerable members of the society through charitable actions. However, these actions and their recipients are chosen by the profit holders, on subjective criteria, according to their moral beliefs and principles. This does not mean that the profit will be redistributed to all the disadvantaged members of the organization/society. Some of these charitable actions are also carried out for selfish purposes, in order to obtain tax reductions.

3. Progressivism considers that organizations are motivated by their own selfish interest, but that they must also consider social responsibility in a broad sense, vis-à-vis the various interest groups affected by the organization's activity.

4. The ethical idealism considers that an organization's main responsibility is towards the stakeholders (employees, society, region, environment), generating forms of organization such as cooperatives, employee-owned companies, community owned public services, etc.

\section{PECULIARITIES REGARDING THE THEORY AND PRACTICE OF APPLYING THE PRINCIPLES OF ETHICS IN THE MANAGEMENT OF THE MILITARY ORGANIZATION}

For the defence and security organizations, managerial ethics and how social responsibility is perceived depend on many factors, with significant country-specific differences. The military organization cannot exist separately from the society, and as a result its ethical values and standards are built starting from the norms, values and standards of the society within which it operates and are subsequently refined and adapted to meet its specific purposes. Thus, the values and standards of military organizations have a dual source: some derive from the society within which they exist (from the civilian society objectives), while others derive from objectives and characteristics specific to the military organization.

Hence, a civilian society that has as a moral guideline the productive approach (e.g. USA), can more easily transfer ideas on the need to use concepts such as productivity, cost-effectiveness, performance indicators, etc. to the military. The use of civilian contractors for outsourcing various activities (feeding, logistical support, arms production, providing security - which may result in the blurring of the dividing lines between regular army and security contractors, such as Blackwater) are specific to this approach. In a country such as China, where the civilian culture is a collectivist one, based on the progressive approach, these activities are considered exclusively the responsibility of the regular army, and the concept of profit is not essential in defense activities. 
The approach of ethical idealism may also exist within the armed forces, deriving from the basic characteristics of the military organization and from its internal objectives. Samuel Finer considers that "the main objective of an army is to wage and win wars". The specific characteristics of the organization derive from this main purpose and are presented in the following figure.

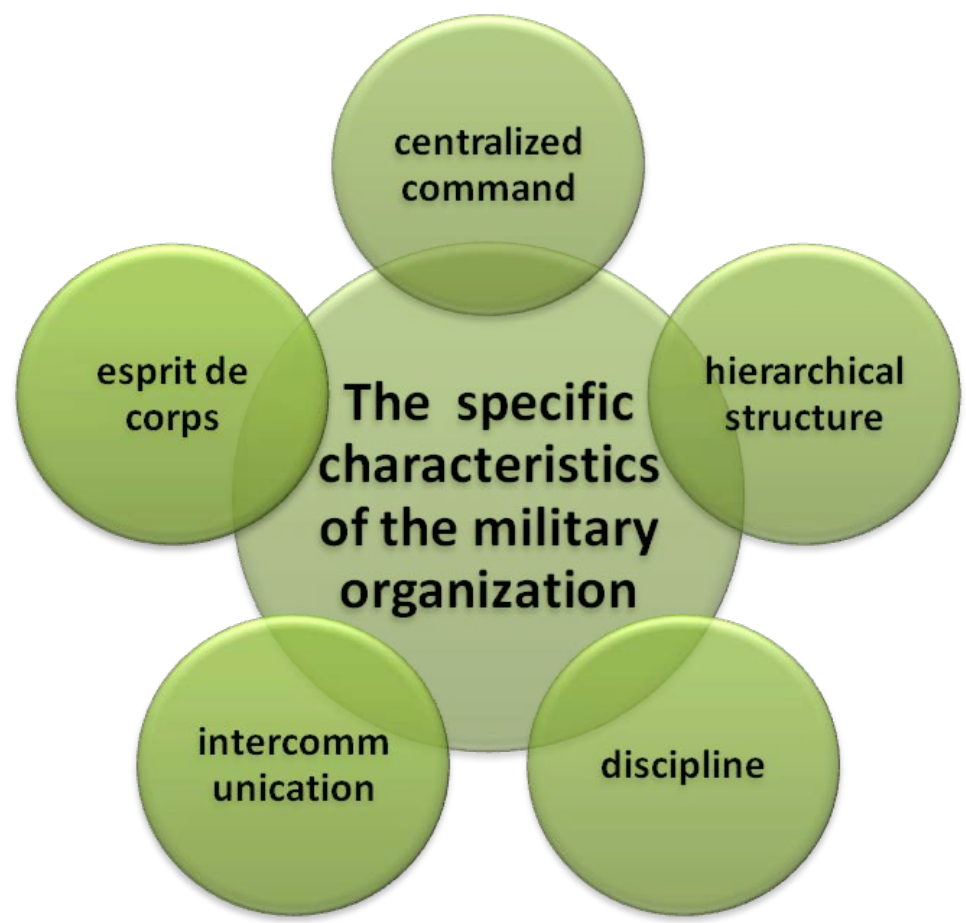

Figure 1. The specific characteristics of the military organization

Source: Adapted from Finer $(1962,7)$

Many of the values promoted in the military organization mentioned above have a positive influence on the ability of the managers to make ethical decisions, but they can also lead to serious issues in some situations.

For example, loyalty towards one's team is a positive trait, encouraged by the military organization, but it can also backfire when it is prioritized over the interests of the organization or the stakeholders. For example, the loyalty towards the team may lead the manager to overlook, disregard or deliberately cover up internal mistakes from external scrutiny (in the form of audit, quality control, financial control, etc). This makes the role of the manager in the military organization crucial, in establishing clear and healthy boundaries about the extent to which team loyalty can be used as a justification for not reporting problems or mistakes, and to the fact that whistle-blowers are not to be considered "traitors" if the problems they are reporting can clearly affect the entire organization.

By definition, the military organization, is characterized by a greater sense of unity than other civilian organizations. The armed forces are supposed to function as a unitary organism, which means that dissent and lack of unity are not to be tolerated. This is achieved by enforcing obedience to the superior rank, loyalty towards peers/team, but also through the construction of a specific culture, based on special codes of honour. Solidarity is enhanced within the military organization, both in terms of what Durkheim $(2013,99)$ calls "organic solidarity" (a system of different and special functions united by definite a relationships) and also through "mechanic solidarity" (a more or less organized ensemble of beliefs and sentiments common to all the members of the group).

The feeling of belonging to a special organization, the tradition of respect and obedience for rank and authority can make the management more effective, but these traits can also have negative 
effects when they promote distrust and even contempt for the "outsiders" - in particular the civilian society. The civilian control over the military is an established feature in many countries, but the feeling of superiority of the military institution or cause over other civilian area may lead to management decisions that may be ethically questionable, especially in terms of the "guns versus butter dilemma" - allocation of public resources to defence area versus other budgetary areas, such as education, health care, infrastructure, etc. Former military filling important decision positions in the public administration/government may be faced with a difficult ethical dilemma - advocate the allocation of scarce public resources according to managerial criteria or according to their personal loyalty towards the military.

The managers within the military may be faced with similar ethical dilemmas. They may have to make choices between their loyalty to the military organization or to their subordinates versus taking tough, but necessary, cost reduction measures. The issue of budget management and cost reductions is often a source of ethical challenges for military managers. These measures may be required as they may benefit the entire society or the entire military organization (as resources are directed to other areas, considered of higher priority at a specific moment), but costs reductions may generate ethical issues for the managers involved, for instance (Schmitt, 2004):

$>$ closing military bases may generate savings, but it also has negative effects on the military personnel and their families;

$>$ cutting maintenance costs may potentially increase the risk of accidents;

$>$ reducing costs by cutting down personnel equipment expenses may increase the risk for military personnel being deployed;

$>$ outsourcing services in order to reduce costs generates job losses for the military staff.

Another feature of the military organization, with direct implications on military managerial ethics, is the centralization of the military command. A strict chain of command links all the components of the military organization, and the centralization of the authority has direct effects on the field of managerial ethics within the army. The pyramidal organization of the authority, the existence of strict regulations, as well as the depersonalization of the authority (which is mainly rank-related) can have both advantages and disadvantages. When clear and specific rules and regulations exist and are applied in a given situation, the ethical dilemmas of a manager are reduced through the existence of a clear framework or an order given by a superior. On the other hand, if a manager considers that a certain decision is un-ethical and does not have a regulatory framework, or if a superior's order conflicts with his / her personal ethical principles, he / she has much less freedom of decision than a manager from a civil organization, with potentially negative consequences on the organization itself or on the external environment

\section{STUDIES AND RESEARCH ON THE PERCEPTION OF MANAGEMENT ETHICS IN THE ROMANIAN MILITARY ENVIRONMENT}

Starting with 2018, the Management Department of the "Nicolae Bălcescu" Land Forces Academy of Sibiu undertook an extensive research study aimed at investigating the current state of development of leadership science in the military, a study that focused on several components of military leadership. The study based on the questionnaire, whose general design is presented in table no. 1, aimed, among other things, at applying the principles of ethics, customized to the specifics of the military organization. 
Table 1. The characteristics of the sample used for the study

\begin{tabular}{|c|c|c|c|}
\hline & Age groups & $\begin{array}{l}\text { Hypothetical managerial } \\
\text { implications }\end{array}$ & Percentage \\
\hline & Under 30 & & $19.1 \%$ \\
\hline & Between 30 and 40 & Respondents from the age & $38.3 \%$ \\
\hline & Between 40 and 50 & category $30-50$ have extensive & $40.5 \%$ \\
\hline & Over 50 & managerial experience & $2.1 \%$ \\
\hline & Total $=47$ & & 100.0 \\
\hline & Age groups & $\begin{array}{c}\text { Hypothetical managerial } \\
\text { implications }\end{array}$ & Percentage \\
\hline$\ddot{\theta}$ & Human resources & & $12.8 \%$ \\
\hline$\stackrel{00}{=}$ & Logistics & & $23.4 \%$ \\
\hline :ie & Financial-accounting & Respondents from the training & $4.3 \%$ \\
\hline 0 & Training and education & and education domain are & $40.4 \%$ \\
\hline 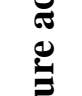 & $\begin{array}{l}\text { Other } \\
\text { support) }\end{array}$ (production $\quad$ and & component of the management & $19.1 \%$ \\
\hline$\underline{\underline{E}}$ & Total $=47$ & & 100.0 \\
\hline 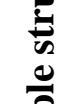 & Managerial experience & $\begin{array}{c}\text { Hypothetical managerial } \\
\text { implications }\end{array}$ & Percentage \\
\hline$\hat{\Xi}$ & Under 5 years & Respondents with a managerial & $21.3 \%$ \\
\hline & Between 5 and 10 years & experience of over 20 years have & $23.4 \%$ \\
\hline & Between 10 and 20 years & a mature comprehension of the & $44.7 \%$ \\
\hline & Over 20 years & processes typifying the military & $10.6 \%$ \\
\hline & Total $=47$ & organization & 100.0 \\
\hline & Academic specialty & $\begin{array}{c}\text { Hypothetical managerial } \\
\text { implications }\end{array}$ & Percentage \\
\hline & $\begin{array}{l}\text { Management of } \\
\text { organizational capabilities }\end{array}$ & Respondents from the & $27.7 \%$ \\
\hline & Postgraduate course & postgraduate course category & $72.3 \%$ \\
\hline & Total $=47$ & ild-management & 100.0 \\
\hline
\end{tabular}

\section{Source: Own research}

According to figure 2, the recorded scores (3.98, 4.13 and 4.15 respectively) to the answers regarding the failure approach highlight the specific character of intolerance to failure, fact supported by the specifics of the missions of this type of organization.

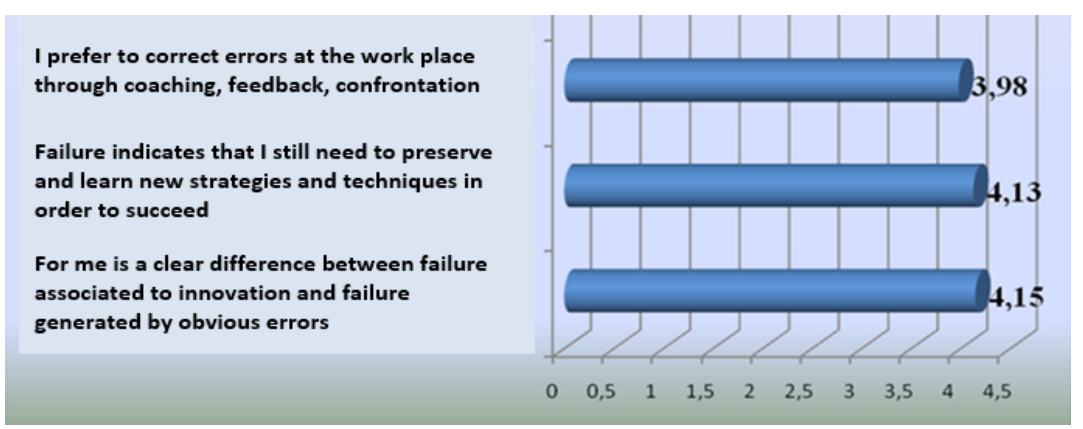

Figure 2. Valorization of failure-related statements

Source: Own research 
The following highlights (figure 3) characteristics regarding the difficulty of ethical behavior, the scores recorded for the statements of a unit showing the robustness of the military organization and of the specific organizational culture.

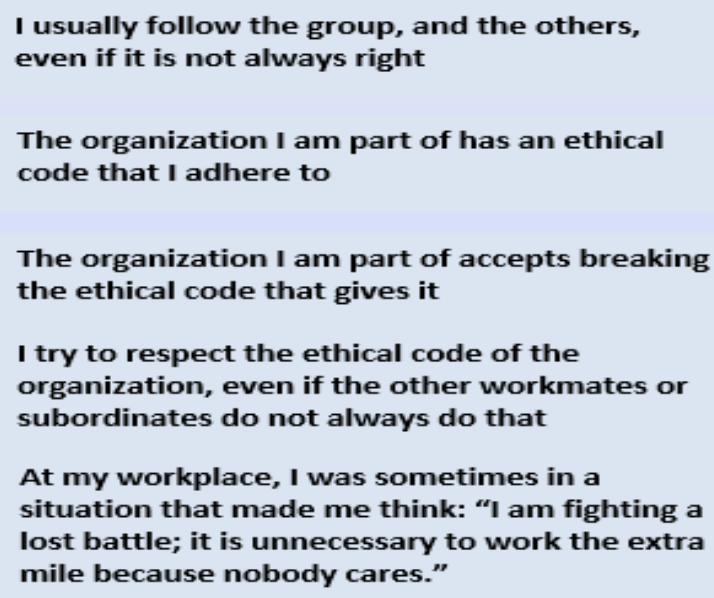

Figure 3. Valorization of statements regarding the difficulty of ethical behavior Source: Own research

In order to be able to compare the fields of activity in terms of the variables analyzed in this study, we eliminated the financial-accounting field, which contained only two subjects. As the remaining four groups are small, an analysis of the homogeneity of the dispersion in each group was performed in the first stage. In each case, the value of the Levene test was insignificant and therefore it can be said that the dispersions within the four groups are homogeneous, which allows the application of the One-way ANOVA procedure.

One-way ANOVA depending on the field of activity. The application of the ANOVA test to evaluate statistically significant differences in the concepts analyzed in this questionnaire, according to field of activity, highlighted the following: the respondents differ in the degree to which they rely in the leadership process on what others have discovered in the past about the "art of leadership". The significant difference appears between the subjects whose field of activity is Logistics ( $\mathrm{m} 2=$ 3.73, sd $=.64$ ) which is based more on the experiences of the forerunners compared to those whose field of activity is production and support $(\mathrm{m} 5=2.67$, sd $=1)$. The difference is statistically significant: $\mathrm{F}(3.41)=3.92, \mathrm{p}=0.015$. The averages obtained by the four fields of activity are presented in the graph below.

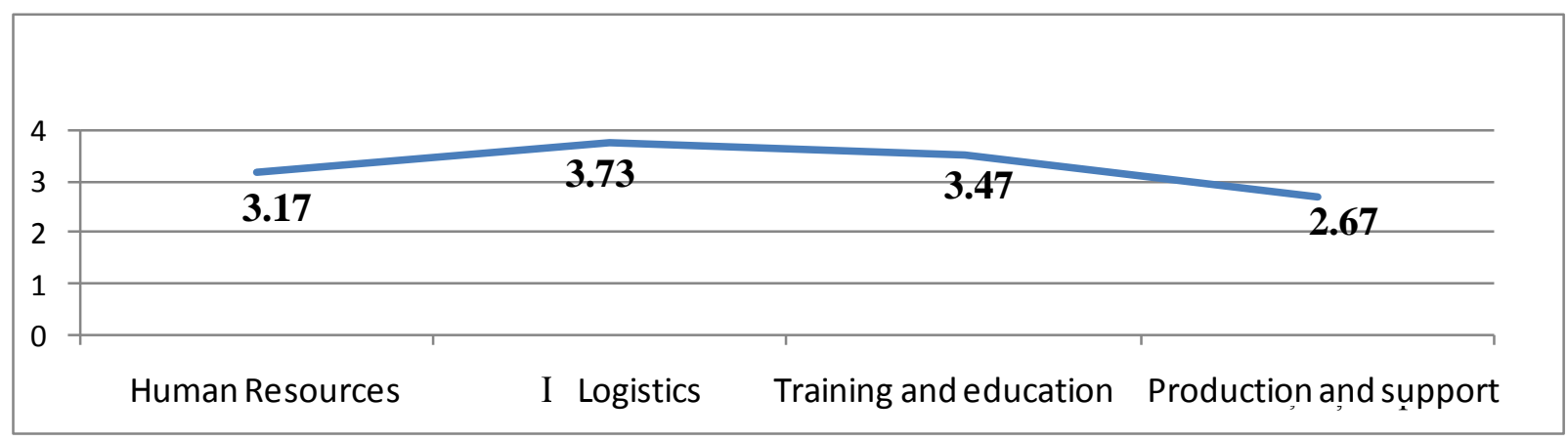

Figure 4. Valorization of statements regarding the consideration of practical managerial values from the past

Source: Own research 
One-way ANOVA depending on managerial experience. The application of the ANOVA test to evaluate the statistically significant differences in the concepts under analysis in this questionnaire, depending on the managerial experience of the subjects, highlighted the following:

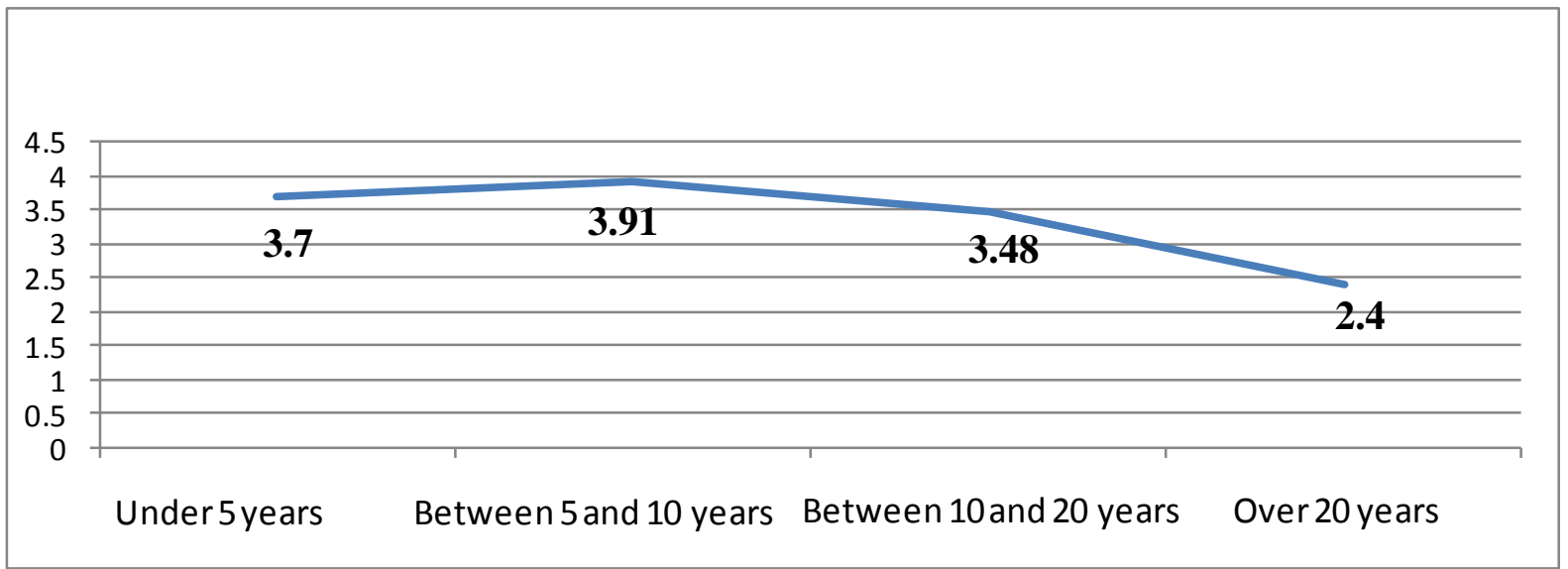

Figure 5. Valorization of statements regarding the consideration of values of managerial experience

Source: Own research

As noted in the figure above, there are significant differences between the subjects surveyed in terms of the degree to which they keep to their habits. Thus, subjects who have a managerial experience over 20 years $(\mathrm{m} 4=2.40$, sd $=.54)$ care less about their habits compared to subjects with a managerial experience under five years $(\mathrm{m} 1=3.70$, sd $=.67)$ and to those with managerial experience between 10 and 20 years $(\mathrm{m} 2=3.91$, $\mathrm{sd}=.70)$. The difference is statistically significant: $\mathrm{F}(3.43)=4.33, \mathrm{p}=0.009$.

\section{CONCLUSIONS}

The interpretation of the results led to the confirmation of the four hypotheses that formed the basis of the scientific approach (presented in table 1) but as a general conclusion, we can mention that the training structure specific to the military environment strongly affects the character and action behavior of military leaders and their perception related to the role of ethics. The rigor and unconditional assumption of the roles entrusted to the organization are essential features for a successful career and, at the same time, for the application of managerial ethics. Participation in missions in theaters of operations (which also imposes an ethic of war) and implicitly, joint participation with alliance partners in the various training or combat actions, the various career and advanced training courses, are as many learning environments that ensure managerial and specialized development and, last but not least, the characteristic development of military leaders, in accordance with the current and future demands of the military.

\section{REFERENCES}

Bentham, J. (1907). An Introduction to the Principles of Morals and Legislation. Oxford: Clarendon Press

Buono, A. F. \& Nicholas, L. (1990). Stockholder and stakeholder interpretations of business' social role. In Michael Hoffman and Jennifer Moore (eds.), Business ethics: Readings and cases in body-rate morality, 2nd ed. New York: McGraw-Hill 
Driver, J. (2014). The History of Utilitarianism. Retrieved June 12, 2020, from https://plato.stanford.edu/entries/utilitarianism-history

Durkheim, E. (2013). De la division du travail social. Paris: Presses Universitaires de France

Finer, S. (1962). The Man on Horseback - the role of military in politics. London: Pall Mall Press Ltd.

Friedman, M. (1962). Capitalism and freedom. Chicago: University of Chicago Press

Frieser, J. (2009). Ethics. Retrieved June 12, 2020, from https://iep.utm.edu/ethics/

Hursthouse, R. \& Zalta, E. N. (eds.) (2003). Virtue ethics. Stanford Encyclopaedia of Philosophy. Retrieved June 18, 2020, from http://plato.stanford.edu/archives/fall2003/entries/ethics-virtue

Johnson, R. \& Cureton, A. (Spring 2019 Edition). Kant's Moral Philosophy. The Stanford Encyclopedia of Philosophy. Retrieved June 18, 2020, from https://plato.stanford.edu/archives/spr2019/entries/kant-moral/>.

Kant, I. (1964). Groundwork of the metaphysics of morals. Translated by H. Paton. New York: Harper \& Row

McCloskey, H. (1965). Rights. Philosophical Quarterly, 15, 115

Rawls, J. (1971). The theory of justice. Cambridge, MA: Harvard University Press

Schmitt, E. (2004, December 8). Iraq-Bound Troops Confront Rumsfeld Over Lack of Armor. The New York Times. Retrieved June 21, 2020, from https://www.nytimes.com/2004/12/08/international/middleeast/iraqbound-troops-confrontrumsfeld-over-lack-of.html

Shue, H. (1981). Basic rights. Princeton, NJ: Princeton University Press

Stoljar, S. (1984). An analysis of rights. New York: Martin’s Press

Tuck, R. (1979). Natural rights theories: Their origin and development. New York: Cambridge University Press

Velasquez, M. G. (1998). Business ethics: Concepts and cases, 4th ed. Englewood Cliffs, NJ: Prentice Hall 